\title{
Protective Effect of Sphaerococcus coronopifolius Crude Extract in Combination with Bacillus Calmette-Guerin on Ligature-Induced Depression in Female Wistar Rats
}

\author{
Fahima Fellah ${ }^{1,2} \otimes$, Rédha Djenidii, ${ }^{2,3}$ and Imen Chebout ${ }^{4}$ \\ 'Département des Sciences Biologiques, Faculté SNV-STU, Université de Bordj Bou Arreridj, Bordj Bou Arreridj, Algérie \\ 2Laboratoire de Biochimie Appliquée, Faculté des Sciences de la Nature et de la Vie, Université de Bejaia, Bejaia, Algérie \\ 3Département des Sciences Agronomiques, Faculté SNV-STU, Université de Bordj Bou Arreridj, Bordj Bou Arreridj, Algérie \\ ${ }^{4}$ Laboratoire de l'anatomie et de Cytopathologie, Faculté de Médecine, Université de Bejaia, Bejaia, Algérie
}

\begin{abstract}
Objective Immunomodulation is a therapeutic technique that modulates the balance of cytokines in the body. In this regard, our experiment was conducted to investigate the potential effect of S. coronopifolius crude extract in combination with low dose of Bacillus CalmetteGuerin (BCG) on depression-like behaviors in female Wistar rats.

Methods Sciatic nerve injury was employed to induce depression and intradermal injection of $0.02 \mathrm{~mL}$ of BCG per rat was administered to lead an activation of innate immune system. Daily intra-peritoneal injections of $25 \mathrm{mg}$ algae extract kg-1 body weight were performed for 14 continuous days. Forced Swimming (FS) and Open Field (OF) tests were conducted to assess despairing and spontaneous behaviors. At the end of the experiment, brain was removed to determine the activities of catalase (CAT) and glutathione-S-transferase (GST), whereas spleen and adrenals were used for the histopathological study.

Results The combined treatment exhibited antidepressant-like activity in FST by reducing immobility time, without inducing any significant change in ambulatory behavior in OFT. The histological analyses of spleen and adrenal structure showed a conserved architecture. Conclusion The results suggested that algae extract produce an antidepressant-like effect in combination with low dose of BCG, which is possibly trigged by its anti-oxidant and anti-inflammatory properties.

Psychiatry Investig 2020;17(2):130-139
\end{abstract}

Key Words Depression, Sciatic nerve, Immunomodulation, BCG, S. coronopifolius.

\section{INTRODUCTION}

Chronic neuropathic pain caused by nerve injury provokes peripheral and central sensitization. ${ }^{1}$ That is, patients with neuropathic pain involve emotional disorders such as anxiety and depression. ${ }^{2}$ As well, depression is an outspread chronic psychiatric disorder that interferes with social life and work performance. ${ }^{3}$ According to World Health Organization (WHO), depression is estimated to become the second leading cause of death and disability in humans by $2020 .{ }^{4}$ The most presently available antidepressant treatments are designed to target the

\footnotetext{
Received: September 11, 2019 Accepted: November 12, 2019

$\triangle$ Correspondence: Fahima Fellah, PhD

Laboratoire de Biochimie Appliquée, Faculté des Sciences de la Nature et de la Vie, Université de Bejaia, Bejaia 06000, Algérie

Tel: +213 551637 283, E-mail: fahimafellah@gmail.com

(c) This is an Open Access article distributed under the terms of the Creative Commons Attribution Non-Commercial License (https://creativecommons.org/licenses/bync/4.0) which permits unrestricted non-commercial use, distribution, and reproduction in any medium, provided the original work is properly cited.
}

serotonergic and/or the noradrenergic system in brain. ${ }^{5} \mathrm{How}-$ ever, many of these antidepressants treatments have a slow onset of action (over 2 weeks) and are effective in only $50 \%$ of patients, with serious adverse reactions. ${ }^{6}$ This may reflect the heterogeneity of the mechanisms underlying depression, drawing attention to novel therapeutic targets that are not addressed by current antidepressants. ${ }^{5}$ Despite the dominance of neurotransmitter research in biological psychiatry, psychoneuroimmunology has developed over recent decades, investigating the role of immune dysfunction and inflammation in major psychiatric disorders. ${ }^{7}$ Conjointly, accumulating evidence suggests that cytokines, critical to the neuroimmune response in neuropathic pain, play a central role in the etiology of depressive symptoms. ${ }^{8}$ Furthermore, rodent models of depression are also associated with elevated levels of inflammation in the periphery and brain. ${ }^{9}$ Thereby, modulation of peripheral inflammation and associated immune signaling pathways may provide an effective way to treat depression. ${ }^{5}$ Immunomodulatory 
drugs may have efficacy for depressive symptoms that are comorbidly associated with inflammatory disorders. ${ }^{10}$ Over time, so many immunomodulators were introduced like adjuvants, cytokines, glucocorticocoids, minerals, herbs, vaccines and others. ${ }^{11}$ The most extensively investigated immunoadjuvant is Bacillus Calmette-Guerin (BCG). ${ }^{12}$ The first observation for the use of BCG in enhancement of immune response was evidenced by use of mycobacteria in preparation of Freund's adjuvant in the late 1950s. ${ }^{13}$ Furthermore, improvement in the efficacy of specific immunotherapy (SIT) has been attempted by the addition of adjuvants, including BCG. ${ }^{14}$

On the other hand, medicinal plants, with lower economic costs and fewer side effects, have proved their curative effect in treating many clinical symptoms, ${ }^{15}$ including mental illness. ${ }^{16,17}$ Indeed, many plants are traditionally used by native people for the treatment of neurological health problems. ${ }^{3}$ Additionally, the special importance of total plant extracts is that they are easily available products, without purification to apply them in possible prevention of diseases. ${ }^{18}$ The red algae Sphaerococcus coronopifolius extract was reported to possess antioxidant, anti-inflammatory, antitumoral and anxiolytic-like activities. ${ }^{19-21}$ The present study was therefore designed to evaluate the potential effects of aqueous extract of $S$. coronopifolius in combination with BCG on depression-like behavior in female Wistar rats.

\section{METHODS}

\section{Algae collection, extract preparation and dose determination}

Algae collection, extract preparation and dose determination was carried out as described previously. ${ }^{21}$ Briefly, S. coronopifolius was collected on submerged rocks at a depth of 6-7 m in Tiskerth, a small Mediterranean islet in the region of Boulimat, Bejaia, Northeastern Algeria. The Global Positioning Systems (GPS) location is $36^{\circ} 48^{\prime} \mathrm{N}, 4^{\circ} 58^{\prime} \mathrm{E}$ and the collected plant was identified in the Laboratory of Botany, University of Bejaia, Algeria. DNA barcoding identification was performed to confirm the taxonomic one at the Phycological Lab of the University of Messina, Italy, where the voucher specimen (No. PHL-FF0002) was deposited. The collected algae was dried, ground and then subjected to extraction with distilled water $(0.1 \mathrm{~g} / 10 \mathrm{~mL})$. After shaking for $1 \mathrm{~h}$ at room temperature and centrifugation at 2,220 rpm during $10 \mathrm{~min}$, the obtained extract was concentrated using a rotary evaporator and stored for the biological tests on animals. Dose determination was performed using the forced swimming test (FST), a standardized test of depressive-like behavior in which depression is inferred from increased duration of immobility. ${ }^{22}$ Three doses of algae extract were tested: 15,25 , and $35 \mathrm{mg} / \mathrm{kg}$ of body weight. On day 1 , an intra-peritoneal injection of algal extract was administered to the animals half an hour after swimming (pre-test). On the second day, two injections were applied, the first one five hours before the test and the second injection one hour before the test. The group with the lowest immobility time was the one treated with a dose of $25 \mathrm{mg} / \mathrm{kg}$ of body weight.

\section{Study animals}

Healthy female Wistar rats $(165 \pm 18 \mathrm{~g})$ were obtained from Pasteur Institute of Algiers. Animals were maintained under standard environmental conditions $\left(24 \pm 1^{\circ} \mathrm{C}, 12: 12 \mathrm{~h}\right.$ dark/light cycle). Food and water were available ad libitum. Animals were handled according to the recommendation of the International Ethic Committees Directive 2010/63/EU and the ethical exigencies of the Faculty of Life and Nature Sciences of the University of Bejaia, Algeria. After three weeks of acclimatization period, female rats were randomly divided into five groups (five rats per group):

Control Group: Have not suffered anything and not treated with any drug.

LIG Group: Ligation (Sciatic nerve ligation under general anesthesia).

LIG+AE Group: Ligatured rats treated with $25 \mathrm{mg}$ algae extract $\mathrm{kg}^{-1}$ body weight.

LIG+BCG Group: Ligatured rats vaccinated with BCG at a dose of $10^{5} \mathrm{CFU}$.

LIG+BCG+AE Group: Ligatured rats vaccinated with BCG vaccine and treated with $25 \mathrm{mg}$ algae extract $\mathrm{kg}^{-1}$ body weight.

During the experiment, animals were weighed every 10 days.

\section{Depression induced by sciatic nerve ligation}

The sciatic nerve ligation was performed following the protocol of Bennett and Xie ${ }^{23}$ modified by Chettoum et al. ${ }^{24}$ Briefly, the animals were deeply anesthetized with a ketamine $(0.3$ $\mathrm{mL} / 100 \mathrm{~g}$ )/largactil (10\%) mixture (intra-peritoneal) and were fixed in the prone position. A tight ligation of sciatic nerve was performed with 6-0 silk suture. The incisions were sutured and animals were then allowed to recover from the anesthesia. Intra-peritoneal injection of an antibiotic in a volume of $0.3 \mathrm{~mL} /$ $250 \mathrm{~g}$ of body weight was administered for five days after surgery to avoid the development of infection or other adverse outcomes.

\section{Application of treatments}

Following a 6-day post-operative recovery period, a daily intra-peritoneal injection of $25 \mathrm{mg} / \mathrm{kg}$ of S. coronopifolius extract at a dose of $25 \mathrm{mg} / \mathrm{kg}$ of body weight was administered for 14 continuous days, at the same time, as previously described. ${ }^{21}$ BCG was inoculated intradermally (ID) as a single dose in a volume $0.02 \mathrm{~mL} /$ rat containing approximately $10^{5} \mathrm{CFU}$ as in- 
dicated by Yang et al. ${ }^{25}$ in day 7 after surgery.

\section{Behavioral assessments}

To analyze depressive and locomotor/exploratory activity, the animals were subjected to the behavioral tests starting at day 20 after surgery (following two weeks of treatment).

\section{Forced swimming test}

Rats were placed in an aquarium (30 cm large; $40 \mathrm{~cm}$ high) containing water at $23 \pm 1^{\circ} \mathrm{C}$. This dimension ensures that the rats can't escape by climbing to the edges of the device. Two swimming sessions were conducted as described by EstradaCamarena et $\mathrm{al}^{2}{ }^{26}$ : an initial 15 -min pre-test, followed by a 5 -min test $24 \mathrm{~h}$ later. The second session was videotaped. After each swimming session, rats were towel dried, placed into heated cages for $30 \mathrm{~min}$, and then returned to their home cages. The time of immobility, climbing and swimming was calculated.

\section{Open field test}

Each animal was placed in the center of the apparatus and was allowed to explore the arena for $5 \mathrm{~min}$. The $5 \mathrm{~min}$ test was videotaped. The open field arena was cleaned with $70 \%$ ethanol after every trial. Time spent in the central area, total distance traveled and the number of rears were calculated.

\section{Organs weights}

After conducting depression-like behavior tests, rats were sacrificed under ether anesthesia and organs (brain, spleen and adrenal glands) were removed, rinsed with $0.9 \%$ saline solution at $4^{\circ} \mathrm{C}$ and weighed. The weight of each organ was standardized to100 g per body weight of animals.

\section{Biochemical assays}

\section{Preparation of tissue homogenate}

The whole intact brain tissue was homogenized in $0.15 \mathrm{M}$ Tris buffer ( $\mathrm{pH} \mathrm{7.4)}$ and centrifuged at $3000 \mathrm{~g}$ at $4^{\circ} \mathrm{C}$ for $30 \mathrm{~min}$. An aliquot of supernatant was collected and stored at $-20^{\circ} \mathrm{C}$ for the determination of protein level, glutathione-S-transferase (GST) and catalase (CAT) activities.

\section{Estimation of Glutathione-S-transferase activity}

GST (EC 2.5.1.18) activity was measured according to the method of Habig et al. ${ }^{27}$ It depends on measuring the conjugation of reaction of 1-chloro-2,4-dinitrobenzene (CDNB) with reduced glutathione. The change in the absorbance was recorded at $340 \mathrm{~nm}$ and enzyme activity was calculated as nanomoles CDNB conjugate formed/min/mg of protein.

\section{Estimation of Catalase activity}

CAT (EC 1.11.1.6) activity was assayed by the method of Aebi. ${ }^{28}$ The reaction mixture for the test contains $20 \mu \mathrm{L}$ of homogenate mixed with $1,255 \mu \mathrm{L}$ of $\mathrm{PBS}$, and the reaction was started by the addition of $725 \mu \mathrm{L}$ of $\mathrm{H}_{2} \mathrm{O}_{2}(54 \mathrm{mmol} / \mathrm{L})$. Change in absorbance is recorded at $240 \mathrm{~nm}$ and the catalase activity is calculated as nanomoles $/ \mathrm{min} / \mathrm{mg}$ of protein.

\section{Protein estimation}

The amount of protein was measured according to the method of Bradford ${ }^{29}$ using bovine serum albumin as a standard.

\section{Histology}

Spleen and adrenal glands were fixed in formalin solution $(10 \% \mathrm{~V} / \mathrm{V})$, then hydrated in ascending grades of ethanol, cleared in xylene, and embedded in paraffin. Sections of $5 \mu \mathrm{m}$ thick were cut and stained with hematoxylin and eosin ( $\mathrm{H} \&$ E) for the histological examination.

\section{Statistical analysis}

Results were expressed as mean \pm standard deviation (SD). All statistical tests were conducted using GraphPad Prism 7.0 (Dr. Harvey Motulsky, San Diego, CA, USA). One-way and two-way analysis of variance (ANOVA) were used following by Tukey's multiple comparison test to compare between groups. $\mathrm{p}<0.05$ was considered statistically significant.

\section{RESULTS}

\section{Behavior analysis}

Results of the forced swimming test are shown in Figure 1. A combined treatment with algae extract and BCG significantly decreased the immobility behavior $[\mathrm{F}(4,17)=14.12$, $\mathrm{p}<$ $0.0001]$. The Tukey test indicated a significant decrease in immobility time in LIG+AE vs. LIG ( $q=7.582, \mathrm{p}=0.0004)$ and $\mathrm{LIG}+\mathrm{BCG}+\mathrm{AE}$ vs. LIG ( $\mathrm{q}=9.223$, $\mathrm{p}<0.0001)$. A significant decrease in immobility time was observed also between LIG+ $\mathrm{BCG}+\mathrm{AE}$ and LIG+BCG groups ( $\mathrm{q}=6.015, \mathrm{p}=0.0042)$. Whereas, no significant changes in immobility time were observed between Control vs. LIG+AE, Control vs. BCG and Control vs. $\mathrm{LIG}+\mathrm{BCG}+\mathrm{AE}$. Significant changes in climbing $[\mathrm{F}(4,17)=$ $12.61, \mathrm{p}<0.0001]$ and swimming behaviors $[\mathrm{F}(4,13)=17.56$, $\mathrm{p}<0.0001]$ were observed. The Tukey test indicated a significant decrease in climbing time in LIG vs. control ( $\mathrm{q}=4.361, \mathrm{p}=$ $0.0462)$ and LIG+BCG vs. control ( $q=4.586, p=0.0337)$. There was a significant increase in climbing time in LIG+AE vs. LIG ( $q=8.567, p=0.0001)$ and no significant changes in LIG+BCG+ $\mathrm{AE}$ vs. LIG+BCG. The Tukey test revealed a significant increase in swimming time in LIG+BCG vs. LIG ( $q=5.785, \mathrm{p}=0.0093$ ), $\mathrm{LIG}+\mathrm{BCG}+\mathrm{AE}$ vs. LIG (q=9.596, $\mathrm{p}=0.0001)$ and LIG+BCG+ 

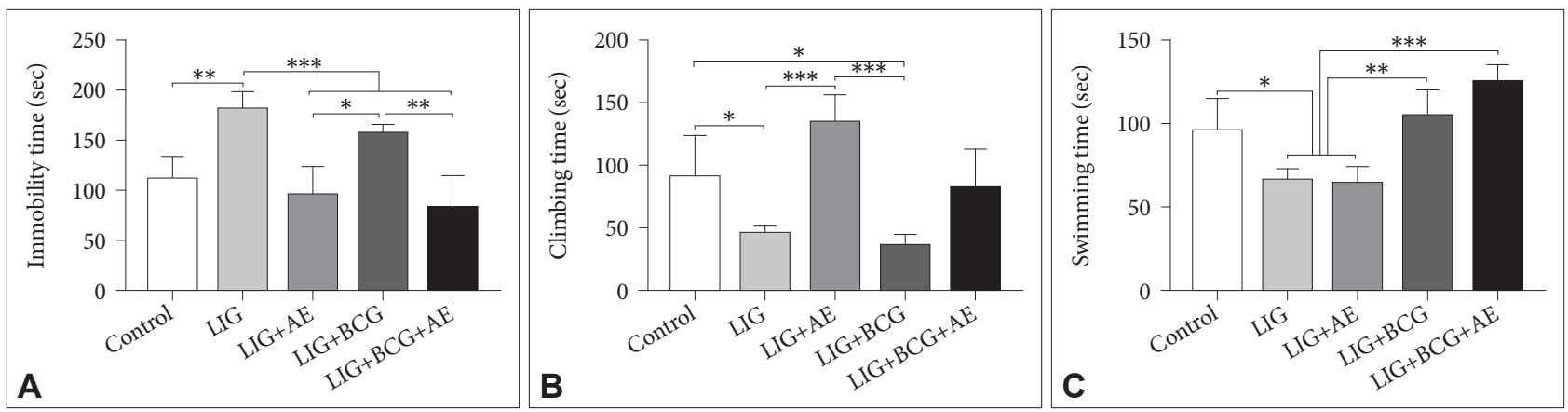

Figure 1. Effect of $A E$ and $B C G$ treatments on forced swimming test parameters in ligatured female Wistar rats (A: Immobility time, B: climbing time, C: swimming time). Data are expressed as mean \pm SD. Comparisons were made using ANOVA followed by post hoc Tukey's multiple comparison test. ${ }^{*} p<0.05,{ }^{* *} p<0.01,{ }^{* * *} p<0.001(n=5)$. LIG: ligation, AE: algae extract, BCG: Bacillus Calmette-Guerin, SD: standard deviation, ANOVA: analysis of variance.
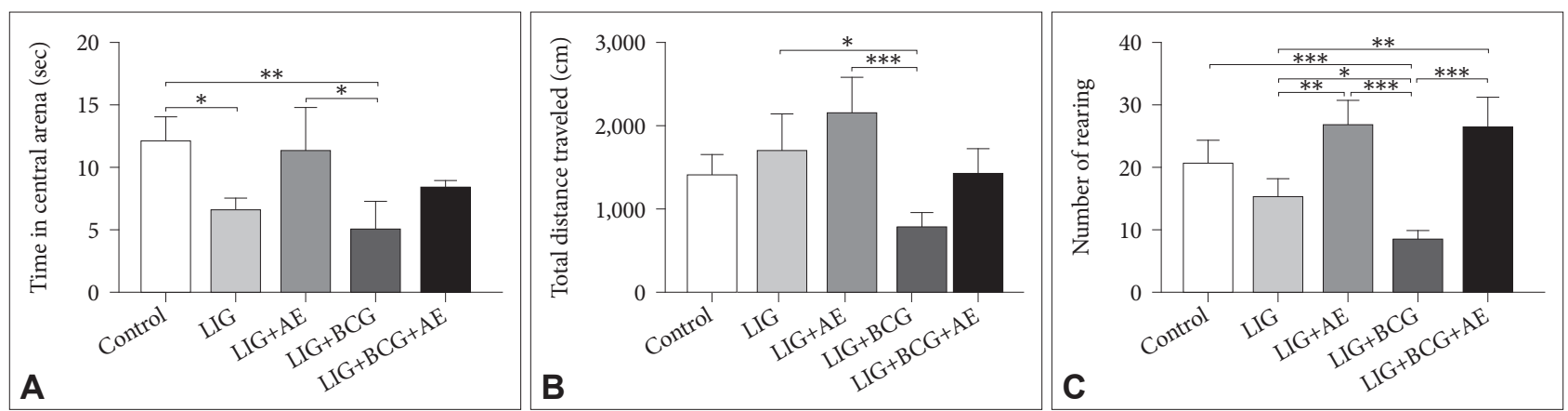

Figure 2. Effect of $A E$ and $B C G$ treatments on the Open Field test parameters in ligatured female Wistar rats (A: time in central area, $B$ : total distance traveled, $\mathrm{C}$ : number of rearing). Data are expressed as mean \pm SD. Comparisons were made using ANOVA followed by post hoc Tukey's multiple comparison test. ${ }^{*} p<0.05,{ }^{* *} p<0.01,{ }^{* *} p<0.001(n=5)$. LIG: ligation, AE: algae extract, BCG: Bacillus Calmette-Guerin, SD: standard deviation, ANOVA: analysis of variance.

AE vs. LIG+AE (q=9.922, $\mathrm{p}<0.0001)$.

The results of the Open Field test showed significant variation in the evaluated parameters as indicated in Figure 2. A significant decrease in time spent in central arena was observed $[F(4,13)=6.661, p=0.0038]$. The Tukey test indicated this decrease in LIG vs. Control ( $\mathrm{q}=4.575, \mathrm{p}=0.0429)$ and in LIG+ BCG vs. Control ( $\mathrm{q}=5.823, \mathrm{p}=0.0088$ ). Moreover, a significant decrease in the total distance traveled was revealed in LIG+ BCG vs. LIG ( $\mathrm{q}=5.591, \mathrm{p}=0.0106)$ and in LIG+BCG vs. LIG+ $\mathrm{AE}(\mathrm{q}=7.647, \mathrm{p}=0.0007)$. Whereas, no significant differences in the total distance travelled had been found between the following four groups: Control, LIG, LIG+AE and LIG+BCG+ $\mathrm{AE}$. Therefore, locomotor activity of rats was not altered by either the surgery or the treatment with algae extract. On the other hand, significant change in number of rearing was revealed $[\mathrm{F}(4,15)=21.1, \mathrm{p}<0.0001]$. A Tukey test indicated a significant decrease in number of rearing in LIG+BCG vs. Con$\operatorname{trol}(\mathrm{q}=7.57, \mathrm{p}=0.0007)$ and in LIG+BCG vs. LIG $+\mathrm{AE}(\mathrm{q}=10.5$, $\mathrm{p}<0.0001)$ and significantly increased in LIG $+\mathrm{AE}$ vs. LIG ( $\mathrm{q}=$ 6.589, $\mathrm{p}=0.0024)$ and in LIG+BCG+AE vs. LIG+BCG ( $\mathrm{q}=$ $10.31, \mathrm{p}<0.0001)$.

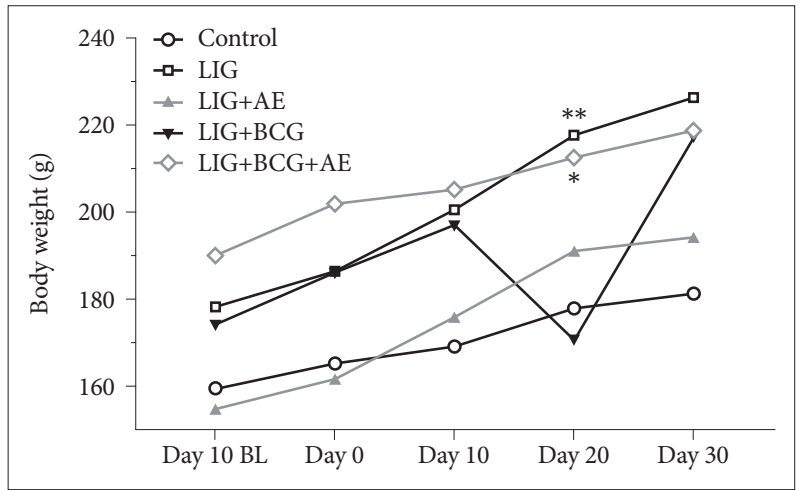

Figure 3. Body weight evolution of female rats during the experimentation. Results were expressed as mean $(n=5)$. Two-way ANOVA. ${ }^{*} p<0.05,{ }^{* *} p<0.01$. LIG: ligation, AE: algae extract, BCG: Bacillus Calmette-Guerin, BL: before ligation, ANOVA: analysis of variance.

\section{Animal body and organ weights}

As shown in Figure 3, body weight of rats increased over time during the experimentation (before and after ligation) in all groups except for LIG+BCG group that induced a significant body weight loss after 10 days post-surgery and 3 days post-treatment LIG+BCG vs. LIG ( $\mathrm{q}=4.985, \mathrm{p}=0.0057)$ and $\mathrm{LIG}+\mathrm{BCG}$ vs. $\mathrm{LIG}+\mathrm{BCG}+\mathrm{AE}(\mathrm{q}=4.436, \mathrm{p}=0.0187)$ and then 
body weight progressively recovered after 20 days.

The results of organs weights showed no significant changes in both spleen $[\mathrm{F}(4,10)=0.936, \mathrm{p}=0.4816]$ and adrenals $[\mathrm{F}$ $(4,10)=2.125, \mathrm{p}=0.1522]$ between all groups despite the fact that LIG and LIG+BCG groups exhibited a slight increase of adrenal glands weight (Figure 4). However, a significant change was observed in brain weight $[\mathrm{F}(4,10)=5.634, \mathrm{p}=0.0122]$. A Tukey test indicated a significant decrease in LIG vs. Control $(\mathrm{q}=5.561, \mathrm{p}=0.0185)$ and LIG+AE vs. Control $(\mathrm{q}=5.462, \mathrm{p}=$ $0.0206)$.

\section{Effects on GST and CAT activities}

Ours results showed significant decrease in GST $[\mathrm{F}(4,19)=$ $178.9, \mathrm{p}<0.0001]$ and CAT $[\mathrm{F}(4,15)=12.42, \mathrm{p}=0.0001]$ activities in all groups compared to the Control (Figure 5). However, there was a slight amelioration in activities of GST in $\mathrm{LIG}+\mathrm{AE}$ and $\mathrm{LIG}+\mathrm{BCG}+\mathrm{AE}$ as well as CAT in $\mathrm{LIG}+\mathrm{AE}$ and $\mathrm{LIG}+\mathrm{BCG}$ groups in comparison with the LIG group.

\section{Histological results}

The histological architecture of spleen was preserved in both
Control and treated group (LIG+AE), the white and the red pulps were normal (Figure 6). Whereas, in the ligatured group (LIG), spleen structure showed a congestion of the red pulp. In the $\mathrm{LIG}+\mathrm{BCG}$ and $\mathrm{LIG}+\mathrm{BCG}+\mathrm{AE}$ groups, as a reaction to the tuberculin, histological sections showed the presence of epitheloid granuloma with Langhans giant cells.

In the Control, $\mathrm{LIG}+\mathrm{AE}$ and $\mathrm{LIG}+\mathrm{BCG}+\mathrm{AE}$ groups, the adrenal glands have displayed normal histology with a large cortical and medullar compartments. The adrenals of both control and treated rat groups, showed normal architecture (Figure 7). However, in the ligatured (LIG) as well as BCG groups, microscopic observation revealed the presence of congestion (Figure 7).

\section{DISCUSSION}

In the present study, behavioral, biochemical and histological approaches were applied to investigate the protective effects of S. coronopifolius crude extract in combination with BCG on ligature-induced depression in female Wistar rats. The choice of females in this study is focused on the fact that
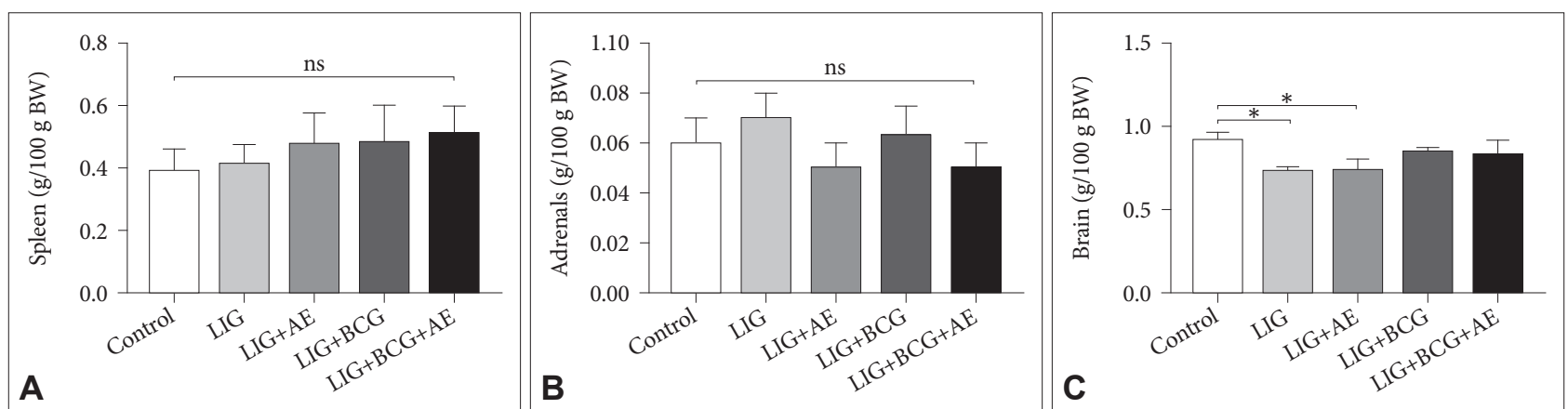

Figure 4. Relative organ weights of rats (A: spleen, $B$ : adrenals, $C$ : brain). Data are expressed as mean \pm SD. Comparisons were made using ANOVA followed by post hoc Tukey's multiple comparison test. ${ }^{*} p<0.05(n=3)$. LIG: ligation, AE: algae extract, BCG: Bacillus CalmetteGuerin, BW: body weight, ns: not significant, SD: standard deviation, ANOVA: analysis of variance.
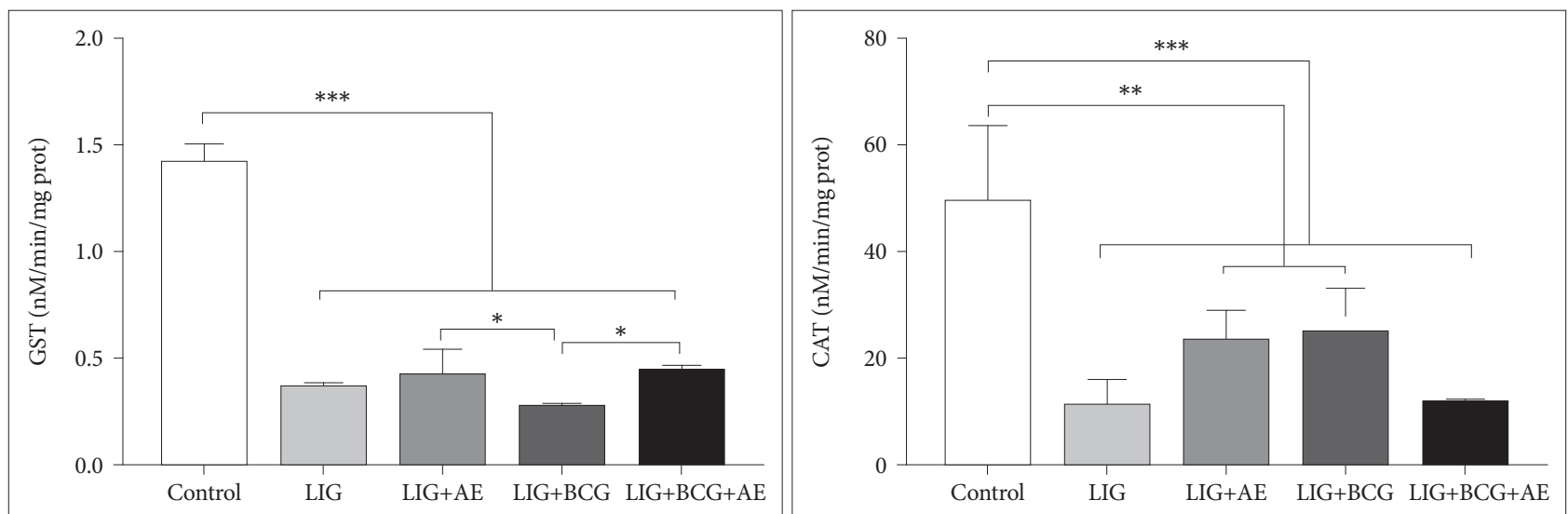

Figure 5. Effect of AE and BCG treatments on the activities of GST and CAT in brain tissue of ligatured female Wistar rats. Data are expressed as mean $\pm \mathrm{SD}$. Comparisons were made using ANOVA followed by post hoc Tukey's multiple comparison test. ${ }^{*} p<0.05$, ${ }^{* *} p<0.01$, ${ }_{* * *}<<0.001(n=3)$. LIG: ligation, AE: algae extract, BCG: Bacillus Calmette-Guerin, GST: Glutathione-S-transferase, CAT: Catalase, SD: standard deviation, ANOVA: analysis of variance. 

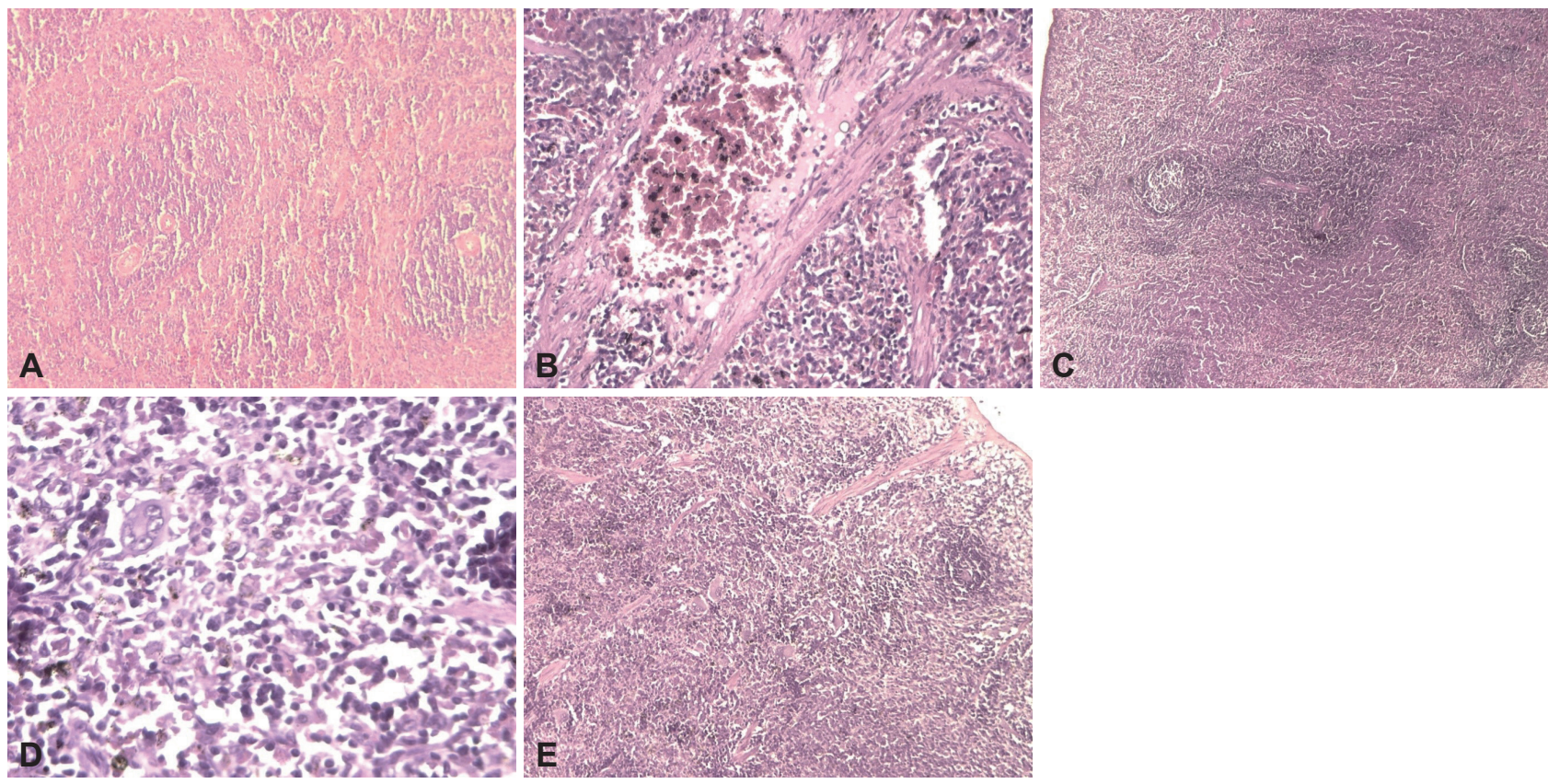

Figure 6. Effect of algae extract and BCG treatments on the morphology of spleen in ligatured female Wistar rats. H\&E staining. A: Control $(\times 10)$, B: LIG $(\times 20)$, C: LIG+AE (×4), D: LIG+BCG $(\times 40)$, E: LIG+BCG+AE (×10). LIG: ligation, AE: algae extract, BCG: Bacillus CalmetteGuerin, H\&E: hematoxylin and eosin.
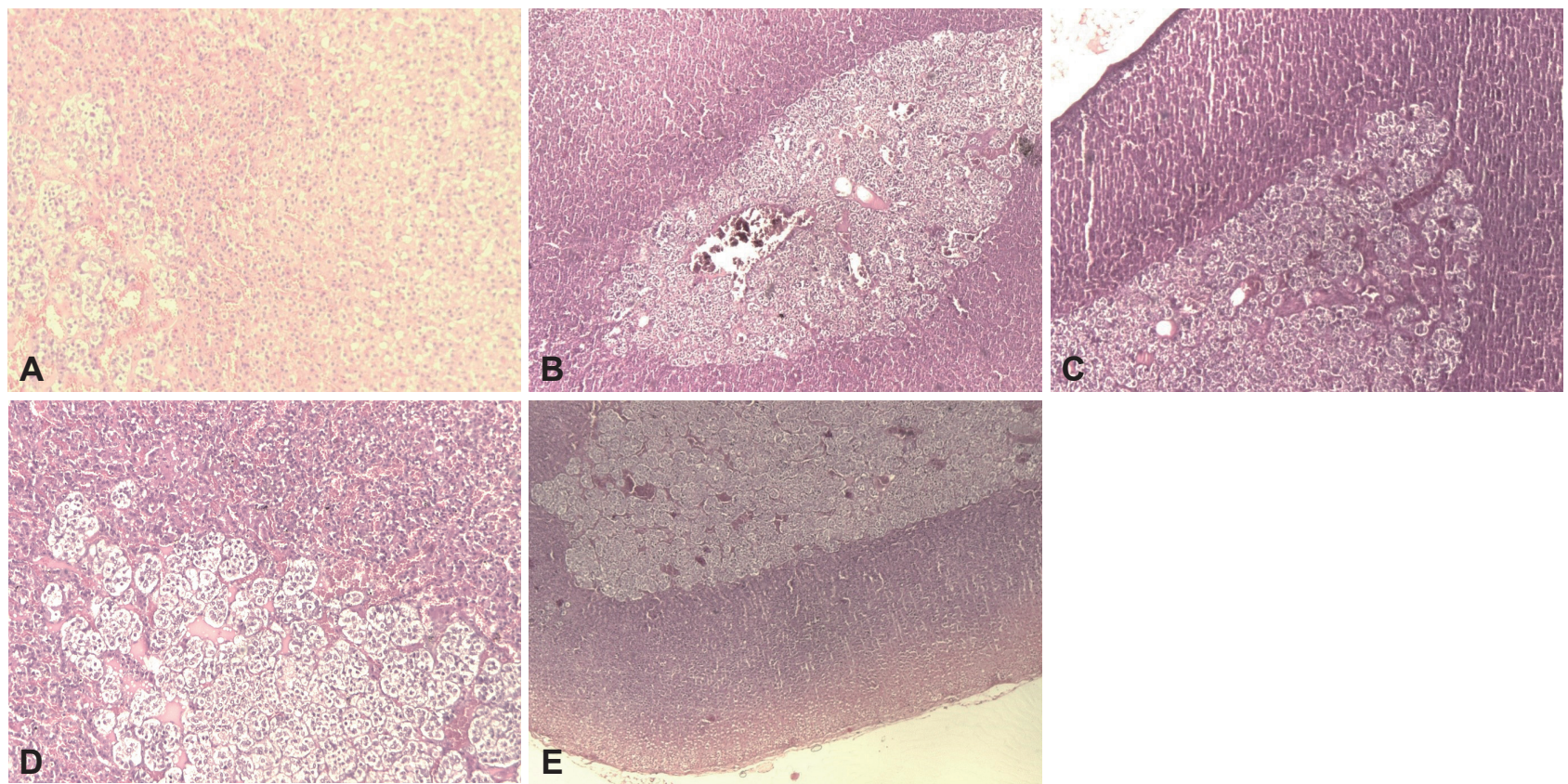

Figure 7. Effect of algae extract and BCG treatments on the morphology of adrenals in ligatured female Wistar rats. H\&E staining. A: Control $(\times 10)$, B: LIG $(\times 4), C:$ LIG+AE $(\times 4), D$ : LIG+BCG $(\times 10), E: L I G+B C G+A E(\times 4)$. LIG: ligation, AE: algae extract, BCG: Bacillus CalmetteGuerin, H\&E: hematoxylin and eosin.

stress is more likely to affect females than males. ${ }^{30,31}$ Previous studies have shown sex differences in pain perception and in the prevalence of chronic pain. ${ }^{32,33}$ In addition, females have a higher prevalence of psychological complications associated with chronic pain. ${ }^{34}$ Furthermore, persistent neuropathic pain is associated with emotional disorders, such as anxiety and depression. ${ }^{1,2}$ Previous reports using rodents have shown that pain lasting more than 4 weeks induces emotional dysfunction, such as anxiety or depression-like behavior. ${ }^{35,36}$ In the present work, depression-like behavior was observed in female Wistar rats 3 weeks after sciatic nerve injury. Our results are in accordance with those of Nishinaka et al. ${ }^{37}$ in which female mice exposed to MSSI (social isolation after weaning) exhibited depression-like behavior within 3 weeks after partial sciatic nerve 
injury (PSL).

Nowadays, natural products, especially polyphenols, have received growing interest due to their potential benefits in treating psychiatric disorders. ${ }^{5}$ In this work, we opted for the use of the crude extract despite the fact that conventional drug development claimed the use of a single active principles isolated from plants. ${ }^{38}$ Nevertheless, there are instances when attempts to isolate the bioactive metabolites from plant extracts ultimately prove fruitless, since overall bioprospecting effects often rely on synergistic and multivalent interactions between plant components. ${ }^{39}$ Therefore, aqueous extract of S. coronopifolius exerted positive effect on depression-like behaviors, which may be related to its richness in antioxidant polyphenols..$^{19}$ Different polyphenolic compounds have been observed to have antidepresssant-like effects in rodents and human. ${ }^{40}$ The substantial antioxidant and anti-inflammatory activities of polyphenols and their ability to modulate synaptic plasticity may contribute to their mechanisms of action. ${ }^{41,42}$

Recently, it has been established that BCG vaccination exerted neuroprotection in several CNS diseases models. ${ }^{43,44}$ Further, its role as an immune adjuvant in the therapy of mood disorders may be more promising. Nevertheless, there are many studies reported that BCG induced a depression-like phenotype in rodents. ${ }^{45,46} \mathrm{In}$ fact, it has been demonstrated that the BCG-induced depressive-like behavior was dose-dependent and the illness (adverse health effect) was observed only in mice receiving no less than $10^{7} \mathrm{CFU} \cdot{ }^{47}$ Accordingly, the role of BCG as an adjuvant has been examined in our study at low dose in a combination with algae, which showed promising results in the treatment of depression. The dose of $10^{5} \mathrm{CFU}$ was selected because of its effectiveness in immune activation, without adverse health effects. ${ }^{25}$ Moreover, it was reported that neonatal BCG vaccination at a dose of $10^{5} \mathrm{CFU}$ elevated neurogenesis, synaptic plasticity, cognitive function, and the levels of neurotrophic factors in mice housed in a standard environment. ${ }^{48}$

The forced swimming test (FST) is a behavioral despair test useful for probing the pathological mechanism of depression and for the evaluation of antidepressant drugs. ${ }^{49}$ Antidepressants achieved their effects by reducing immobility time and increase or prolong active escape behaviors. ${ }^{39}$ It has been shown that the antidepressant-like actions in FST, which were mediated by the stimulation of 5-HT neurotransmission, induced the increase of active swimming period, whereas the augmentation of NE neurotransmission was related to the enhanced climbing activity. ${ }^{50}$ In our study, treatment with algae extract produced a decrease in immobility time accompanied by an increase in climbing time, which suggest the stimulation of the neurotransmission mediated by NE. Noradrenaline plays an important role in the pathophysiology of depression and is used as an effective treatment target..$^{39}$ However, the combined treatment with algae extract and BCG showed an increase in swimming time, which indicate the activation of 5-HT receptors. As well, several antidepressants produce their effect by modulation of brain 5-HT levels. ${ }^{39}$ It is important to point out that there is no significant difference in immobility time between the group treated by algae extract alone and that treated by the combination treatments, which suggest that immunomodulatory responses that might have been induced by BCG require more than two weeks.

The open field test (OFT) is used in combination with the FST to discard non-specific actions of antidepressant treatments. ${ }^{51}$ It was reported that drugs inducing increase in motor activity may give a 'false' positive effect. ${ }^{52}$ This test evaluates the reaction of an animal towards a new and spacious environment. It creates a conflict between the tendency of rodents to find a place to hide, and their aversion to open spaces. ${ }^{53}$ The results from open field test suggested that the combination of algae extract and BCG, at the doses that produced an anti-immobility response, did not show significant locomotor stimulation or inhibition. Therefore, the reported antidepressant-like effect of these treatments was not due to its psychostimulant action. ${ }^{54}$ It has been reported also that low-molecular proanthocyanidins from grapes, applied to mice, exerted antidepressant-like effects in behavioral despair tests but did not affect locomotor activity. ${ }^{55}$ Our results have showed that the combination of algae extract with BCG increased rearing in comparison with non-treated rats, which supports the antidepressant-like activity of this this combination. It has been found that normal rats show increased rearing and grooming in a novel open field, which is driven by the instinct interests of rats to explore a novel environment. ${ }^{56}$

Latterly, oxidative stress was linked with pathophysiology of depression. Oxidative stress damage involves the oxidation of proteins, nucleic acids, membrane lipids, etc. by free radicals, leading to cell degeneration and even death, which is one of the important mechanisms of depression. ${ }^{57}$ The brain has a large potential oxidative capacity but a limited ability to counteract oxidative stress. Cells in the central nervous system are more sensitive to toxic effects of ROS, than cells in other organs of the body.$^{58}$ The present study revealed an important decrease in GST and CAT activities in brain tissue of ligated female rats. It should be noted also that after 2 weeks of treatment with algae extract in combination with BCG, GST and CAT activities remain significantly lower than that in the control group. In line with our results, Sarandol et al. ${ }^{59}$ showed that six weeks of antidepressant treatment with either reboxetine, sertraline, or venlafaxine did not change oxidative-antioxidative system parameters. Furthermore, it was suggested that long-term treatment of at least 12 weeks is needed for oxidative and anti-ox- 
idative system parameters to be changed. ${ }^{60}$

Currently, increased appetite and weight gain have been identified as a common symptom of depression as well as other disorders involving emotional distress. ${ }^{61}$ In our study, the female rats with depression showed an increased body mass. Indeed, studies on animals under stress conditions have pointed out that food intake could be either stimulated or inhibited. ${ }^{62,63}$ In contrast, it was observed a decrease in body weight in LIG+ BCG group 3 days after BCG inoculation accompanied with a decrease in motor activity. These core symptoms constitute the sickness behavior, or behavioral changes that accompany immune response. ${ }^{64}$ However, these sickness behaviors return to normal by a few days after inoculation of BCG. ${ }^{22,47}$ In our case, the female rats started to regain weight 2 weeks after inoculation. Interestingly, the group treated with a combination of algae extract and BCG showed a balance of body weight, which suggest the beneficial effects of algae extract on sickness behaviors- induced by inoculation of BCG.

The histological analysis of the spleen is particularly important because it gives insight to the presence of the spleen structural components that make the cell potential on which depends its defensive function. ${ }^{65}$ Chronic stress has been described to induce structural alterations in splenic lymphoid tissue in rats. ${ }^{66}$ Granulomatous inflammation, which is a distinctive pattern of chronic inflammatory reaction characterized by focal accumulation of activated macrophages, can generally develop an epitheloid appearance. ${ }^{67}$ Epitheloid cells can fuse to form giant cells with diameter of $40-50 \mu \mathrm{m}$. These giant cells have a large mass of cytoplasm with 20 or more nuclei arranged haphazardly or in a horseshoe pattern peripherally-the Langhans type. ${ }^{67}$ Along with, chronic stress is known to promote a disruption of the HPA axis, usually indicated by increased levels of corticosterone in the serum of rodents. ${ }^{68}$ Thus, hypertrophy of the adrenal gland was observed. ${ }^{69}$ In the present investigation, increased adrenal activity as shown by increased adrenal weight in ligatured rats indicate the activation of the HPA axis. Nonetheless, normal weight of adrenal gland in rats treated by $S$. coronopifolius extract alone or combined with BCG indicated that these treatments prevented the depression-induced activation of adrenocortical activity. Supplementary, the repeat restraint and exogenous corticosterone have low adrenal gland weight. ${ }^{66}$

In summary, the present study examined the mechanisms of the potential antidepressant-like actions for S. coronopifolius extract in combination with low dose of BCG. This study elicited algae extract as the principal drug for the treatment, whereas BCG served as an adjuvant. Our results provides the first evidence indicating that aqueous extract of S. coronopifolius exhibited antidepressive-like effect while BCG inoculation provided no significant benefit, suggesting that immunomod- ulatory responses that might have been induced by BCG require more than two weeks. Obviously, the combination treatment of algae extract with BCG can attenuated depression-like behaviors in stressed female rats through its anti-oxidant and anti-inflammatory properties following at least three weeks. Further investigations should be geared towards using herbal immunomodulators in order to evaluate a potential synergistic effect with algae extract in the treatment of depression.

\section{Acknowledgments}

The authors would like to thank Pr. Morabito Marina and all the team of Phycological Lab of the University of Messina, Italy, for their contribution in the identification by DNA barcoding of the used algae.

This research did not receive any specific grant from funding agencies in the public, commercial, or not-for-profit sectors.

\section{Conflicts of Interest}

The authors have no potential conflicts of interest to disclose.

\section{Author Contributions}

Conceptualization: Rédha Djenidi. Data curation: Fahima Fellah. Formal analysis: Fahima Fellah, Imen Chebout. Investigation: Fahima Fellah, Rédha Djenidi. Methodology: Fahima Fellah, Imen Chebout. Project administration: Fahima Fellah, Rédha Djenidi. Resources: Fahima Fellah, Rédha Djenidi. Software: Fahima Fellah. Supervision: Rédha Djenidi, Imen Chebout. Validation: Rédha Djenidi. Visualization: Fahima Fellah, Imen Chebout. Writing-original draft: Fahima Fellah. Writing-review \& editing: Fahima Fellah, Rédha Djenidi, Imen Chebout.

\section{ORCID iDs}

Fahima Fellah

Rédha Djenidi

https://orcid.org/0000-0002-3312-4339

Imen Chebout

https://orcid.org/0000-0002-1742-0330

https://orcid.org/0000-0003-4070-6799

\section{REFERENCES}

1. Díaz AF, Polo S, Gallardo N, Leánez S, Pol O. Analgesic and antidepressant effects of Oltipraz on neuropathic pain in mice by modulating microglial activation. J Clin Med 2019;8. pii: E890.

2. Ferreira-Chamorro P, Redondo A, Riego G, Leánez S, Pol O. Sulforaphane inhibited the nociceptive responses, anxietyand depressive-like behaviors associated with neuropathic pain and improved the anti-allodynic effects of morphine in mice. Front Pharmacol 2018;9:1332.

3. Akkol EK, Tugçe F, Dereli G, Ilhan M. Assessment of antidepressant effect of the aerial parts of micromeria myrtifolia Boiss. \& Hohen on mice. Molecules 2019;24. pii: E1869.

4. Rutledge RB, Moutoussis M, Smittenaar P. Association of neural and emotional impacts of reward prediction errors with major depression. JAMA Psychiatry 2017;74:790-797.

5. Wang J, Fernández AE, Tiano S, Huang J, Floyd E, Poulev A, et al. An extract of Artemisia dracunculus L. promotes psychological resilience in a mouse model of depression. Oxid Med Cell Longev 2018;2018: 7418681.

6. Park SW, Kim YK, Lee JG, Kim SH, Kim JM, Yoon JS, et al. Antidepressant-like effects of the traditional Chinese medicine kami-shoyosan in rats. Psychiatry Clin Neurosci 2007;61:401-406.

7. Müller N. Immunological aspects of the treatment of depression and schizophrenia. Dialogues Clin Neurosci 2017;19:55-63.

8. Lees JG, Fivelman B, Duffy SS, Makker PSS, Perera CJ, Moalem-Taylor G. Cytokines in neuropathic pain and associated depression. Mod Trends Pharmacopsychiatry 2015;30:51-66.

9. Remus JL, Dantzer R. Inflammation models of depression in rodents. 
Relevance to psychotropic drug discovery. Int J Neuropsychopharmacol 2016;19. pii: pyw028.

10. Wittenberg GM, Stylianou A, Zhang Y, Sun Y, Gupta A, Jagannatha PS, et al. Effects of immunomodulatory drugs on depressive symptoms: a mega-analysis of randomized, placebo-controlled clinical trials in inflammatory disorders. Mol Psychiatry 2019 [Epub ahead of print].

11. Dhama K, Saminathan M, Jacob SS, Singh M, Karthik K, Amarpal, et al. Effect of immunomodulation and immunomodulatory agents on health with some bioactive principles, modes of action and potent biomedical applications. Int J Pharmacol 2015;11:253-290.

12. Farquhar D, Loo TL, Gutterman JU, Hersh EM, Luna MA. Inhibition of drug-metabolizing enzymes in the rat after Bacillus Calmette-Guérin treatment. Biochem Pharmacol 1976;25:1529-1535.

13. Iqbal NT, Hussain R. Non-specific immunity of BCG vaccine: a perspective of BCG immunotherapy. Trials Vaccinol 2014;3:143-149.

14. Cohon A, Arruda LK, Martins MA, Guilherme L, Kalil J. Evaluation of BCG administration as an adjuvant to specific immunotherapy in asthmatic children with mite allergy. J Allergy Clin Immunol 2007; 120:210-213.

15. Li X, Wu T, Yu Z, Li T, Zhang J, Zhang Z, et al. Apocynum venetum leaf extract reverses depressive-like behaviors in chronically stressed rats by inhibiting oxidative stress and apoptosis. Biomed Pharmacother 2018;100:394-406.

16. Bahramsoltani R, Farzaei MH, Farahani MS, Rahimi R. Phytochemical constituents as future antidepressants: a comprehensive review. Rev Neurosci 2015;26:699-719.

17. Farahani MS, Bahramsoltani R, Farzaei MH, Abdollahi M, Rahimi R. Plant derived natural medicines for the management of depression: an overview of mechanisms of action. Rev Neurosci 2015;26:305-321.

18. Ramadan KS, Farid HEA, Almarashi RMM. Antidepressant-like effects of aqueous extract of Salvadora persica in rat model of depression. J Diabetes Metab 2016;7:697.

19. Fellah F, Louaileche H, Dehbi-Zebboudj A, Touati N. Seasonal variations in the phenolic compound content and antioxidant activities of three selected species of seaweeds from Tiskerth islet, Bejaia, Algeria. J Mater Environ Sci 2017;8:4451-4456.

20. Salhi G, Zbakh H, Moussa H, Hassoun M, Bochkov V, Ciudad CJ. Antitumoral and anti-inflammatory activities of the red alga Sphaerococcus coronopifolius. Eur J Integr Med 2018;18:66-74.

21. Fellah F, Djenidi R, Dehbi-Zebboudj A, Frih H, Kerdouche B. Effect of Sphaerococcus coronopifolius Stackhouse 1797 on anxiety-like behavior induced by sciatic nerve ligation in female Wistar rats. Int J Pharma Bio Sci 2018;9:214-222.

22. O'Connor JC, Lawson MA, André C, Briley EM, Szegedi SS, Lestage J, et al. Induction of IDO by bacilli Calmette-Guérin is responsible for development of murine depressive-like behavior. J Immunol 2009;182: 3202-3212.

23. Bennett GJ, Xie YK. A peripheral mononeuropathy in rat that produces disorders of pain sensation like those seen in man. Pain 1988;33:87-107.

24. Chettoum A, Fraia A, Frih H, Ali Rachedi B, Zaafour M, Guernine S, et al. Physiologic and behavioral assessment of sciatic nerve injury in Wistar rat model treated with Freund's Incomplete Adjuvant. Glob Vet 2015;15:1-9.

25. Yang J, Qi F, Gu H, Zou J, Yang Y, Yuan Q, et al. Neonatal BCG vaccination of mice improves neurogenesis and behavior in early life. Brain Res Bull 2016;120:25-33.

26. Estrada-Camarena E, Fernandez-Guasti A, Lopez-Rubalcava C. Interaction between estrogens and antidepressants in the forced swimming test in rats. Psychopharmacology (Berl) 2004;173:139-145.

27. Habig WH, Pabst MJ, Jakoby WB. Glutathione-S-transferase the first step in mercapturic acid formation. J Biol Chem 1974;249:7130-7139.

28. Aebi H. Catalase in vitro. Methods Enzymol 1984;105:121-126.

29. Bradford M. A rapid and sensitive method for the quantities of microgram quantities of protein utilizing the principle of protein binding. Anal Biochem 1976;72:248-254.
30. Donner NC, Lowry CA. Sex differences in anxiety and emotional behavior. Pflugers Arch 2013;465:601-626.

31. Valentino RJ, Reyes B, Van Bockstaele E, Bangasser D. Molecular and cellular sex differences at the intersection of stress and arousal. Neuropharmacology 2012;62:13-20.

32. Mogil JS. Sex differences in pain and pain inhibition: multiple explanations of a controversial phenomenon. Nat Rev Neurosci 2012;13:859866.

33. Bartley EJ, Fillingim RB. Sex differences in pain: a brief review of clinical and experimental findings. Br J Anaesth 2013;111:52-58.

34. Tsang A, Von Korff M, Lee S, Alonso J, Karam E, Angermeyer MC, et al. Common chronic pain conditions in developed and developing countries: gender and age differences and comorbidity with depressionanxiety disorders. J Pain 2008;9:883-891.

35. Zhao X, Wang C, Zhang JF, Liu L, Liu AM, Ma Q, et al. Chronic curcumin treatment normalizes depression-like behaviors in mice with mononeuropathy: involvement of supraspinal serotonergic system and GABAA receptor. Psychopharmacology (Berl) 2014;231:2171-2187.

36. Alba-Delgado C, Cebada-Aleu A, Mico JA, Berrocoso E. Comorbid anxiety-like behavior and locus coeruleus impairment in diabetic peripheral neuropathy: a comparative study with the chronic constriction injury model. Prog Neuropsychopharmacol Biol Psychiatry 2016;71: 45-56.

37. Nishinaka T, Kinoshita M, Nakamoto K, Tokuyama S. Sex differences in depression-like behavior after nerve injury are associated with differential changes in brain-derived neurotrophic factor levels in mice subjected to early life stress. Neurosci Lett 2015;592:32-36.

38. Heinrich M, Barnes J, Gibbons S, Williamson E. Fundamentals of Pharmacognosy and Phytotherapy. London: Churchill Livingstone; 2004.

39. Siddiqui PJA, Khan A, Uddin N, Khaliq S, Rasheed M, Nawaz S, et al. Antidepressant-like deliverables from the sea: evidence on the efficacy of three different brown seaweeds via involvement of monoaminergic system. Biosci Biotechnol Biochem 2017;81:1369-1378.

40. Rahmati B, Kiasalari Z, Roghani M, Khalili M, Ansari F. Antidepressant and anxiolytic activity of Lavandula officinalis aerial parts hydroalcoholic extract in scopolamine-treated rat. Pharm Biol 2017;55:958965.

41. Sureda A, Tejada S. Polyphenols and depression: from chemistry to medicine. Curr Pharm Biotechnol 2015;16:259-264.

42. Elmann A, Wang CK, Vauzour D. Polyphenols targeting brain cells longevity, brain's redox status and neurodegenerative diseases. Oxid Med Cell Longev 2018;2018:7402795.

43. Laćan G, Dang H, Middleton B, Horwitz MA, Tian J, Melega WP, et al. Bacillus Calmette-Guerin vaccine-mediated neuroprotection is associated with regulatory T-cell induction in the 1-methyl-4-phenyl-1,2,3,6tetrahydropyridine mouse model of Parkinson's disease. J Neurosci Res 2013;91:1292-1302.

44. Bourdette D, Naismith RT. BCG vaccine for clinically isolated syndrome and MS: infections and protective immunity. Neurology 2014; 82:15-16.

45. Kelley KW, O’Connor JC, Lawson MA, Dantzer R, Rodriguez-Zas SL, McCusker RH. Aging leads to prolonged duration of inflammationinduced depression-like behavior caused by Bacillus Calmette-Guerin. Brain Behav Immun 2013;32:63-69.

46. Vijaya Kumar K, Rudra A, Sreedhara MV, Siva Subramani T, Prasad DS, Das ML, et al. Bacillus Calmette-Guerin vaccine induces a selective serotonin reuptake inhibitor (SSRI)-resistant depression like phenotype in mice. Brain Behav Immun 2014;42:204-211.

47. O'Connor JC, Andre C, Wang Y, Lawson MA, Szegedi SS, Lestage J, et al. Interferon-gamma and tumor necrosis factor-alpha mediate the upregulation of indoleamine 2,3-dioxygenase and the induction of depressive-like behavior in mice in response to bacillus CalmetteGuerin. J Neurosci 2009;29:4200-4209.

48. Qi F, Zuo Z, Yang J, Hu S, Yang Y, Yuan Q, et al. Combined effect of $B C G$ vaccination and enriched environment promote neurogenesis 
and spatial cognition via a shift in meningeal macrophage M2 polarization. J Neuroinflammation 2017;14:32.

49. Hsu LC, Ko YJ, Cheng HY, Chang CW, Lin YC, Cheng YH, et al. Antidepressant-like activity of the ethanolic extract from Uncaria lanosa Wallich var. appendiculata Ridsd in the forced swimming test and in the tail suspension test in mice. Evid Based Complement Alternat Med 2012;2012:497302

50. Detke MJ, Rickels M, Lucki I. Active behaviors in the rat forced swimming test differentially produced by serotonergic and noradrenergic antidepressants. Psychopharmacology (Berl) 1995;121:66-72.

51. Cito MC, Silva MI, Santos LK, Fernandes ML, Melo FH, Aguiar JA, et al. Antidepressant-like effect of Hoodia gordonii in a forced swimming test in mice: evidence for involvement of the monoaminergic system. Braz J Med Biol Res 2015;48:57-64

52. Borsini F, Meli A. Is the forced swimming test a suitable model for revealing antidepressant activity. Psychopharmacology (Berl) 1988;94: 147-160.

53. Frih H, Bensaci L, Djenidi R, Ali Rachedi B, Tahraoui A, Fisson S. Freund's Complete Adjuvant (FCA) could reverse the depressive-like symptoms induced by Chronic Mild Stress (CMS) in mice. J Neurol Neurophysiol 2013;4:143.

54. Serefko A, Szopa A, Wlaz A, Wosko S, Wlaz P, Poleszak E. Synergistic antidepressant-like effect of the joint administration of caffeine and NMDA receptor ligands in the forced swim test in mice. J Neural Transm (Vienna) 2016;123:463-472.

55. Xu Y, Li S, Chen R, Li G, Barish PA, You W, et al. Antidepressant-like effect of low molecular proanthocyanidin in mice: involvement of monoaminergic system. Pharmacol Biochem Behav 2010;94:447-453.

56. Zhou D, Jin H, Lin HB, Yang XM, Cheng YF, Deng FJ, et al. Antidepressant effect of the extracts from Fructus akebiae. Pharmacol Biochem Behav 2010;94:488-495.

57. Miao M, Peng M, Chen H, Liu B. Effects of Baihe Dihuang powder on chronic stress depression rat models. Saudi J Biol Sci 2019;26:582-588.

58. Trebatická J, Duracková Z. Psychiatric disorders and polyphenols: can they be helpful in therapy. Oxid Med Cell Longev 2015;2015:248529.

59. Sarandol A, Sarandol E, Eker SS, Erdinc S, Vatansever E, Kirli S. Major depressive disorder is accompanied with oxidative stress: short-term antidepressant treatment does not alter oxidative-antioxidative sys- tems. Hum Psychopharmacol 2007;22:67-73.

60. Baek SE, Lee GJ, Rhee CK, Rho DY, Kim DH, Huh S, et al. Decreased total antioxidant activity in major depressive disorder patients non-responsive to antidepressant treatment. Psychiatry Investig 2016;13:222226.

61. Privitera, GJ, Misenheimer ML, Doraiswamy PM. From weight loss to weight gain: appetite changes in major depressive disorder as a mirror into brain-environment interactions. Front Psychol 2013;4:873.

62. Foster MT, Solomon MB, Huhman KL, Bartness TJ. Social defeat increases food intake, body mass, and adiposity in Syrian hamsters. Am J Physiol Regul Integr Comp Physiol 2006;290:R1284-R1293.

63. Jeong JY, Lee DH, Kang SS. Effects of chronic restraint stress on body weight, food intake, and hypothalamic gene expressions in mice. Endocrinol Metab (Seoul) 2013;28:288-296.

64. Garcia-Bonacho M, Esquifino AI, Castrillon PO, Toso CR, Cardinali DP. Age-dependent effect of Freund's adjuvant on 24-hour rhythms in plasma prolactin, growth hormone, thyrotropin, insulin, follicle-stimulating hormone, luteinizing hormone and testosterone in rats. Life Sci 2000;66:1969-1977.

65. Mitevska E, Kostadinova-Petrova I, Kostovska N. Changes of spleen in wistar rats exposed to therapeutic doses of dexamethasone and medroxyprogesterone acetate evaluated by stereological parameters. Pril (Makedon Akad Nauk Umet Odd Med Nauki) 2015;36:13-25.

66. Hernandez ME, Martinez-Mota L, Salinas C, Marquez-Velasco R, Hernandez-Chan NG, Morales-Montor J, et al. Chronic stress induces structural alterations in splenic lymphoid tissue that are associated with changes in corticosterone levels in Wistar-Kyoto rats. BioMed Res Int 2013; Article ID 868742.

67. Kumar SN, Prasad TS, Narayan PA, Muruganandhan J. Granuloma with langhans giant cells: an overview. J Oral Maxillofac Pathol 2013; 17:420-423.

68. Gądek-Michalska A, Spyrka J, Rachwalska P, Tadeusz J, Bugajski J. Influence of chronic stress on brain corticosteroid receptors and HPA axis activity. Pharmacol Rep 2013;65:1163-1175.

69. Géa LP, Colombo R, da Rosa ED, Antqueviezc B, de Aguiar EZ, Hizo $\mathrm{G}$, et al. Anhedonic-like behavior correlates with IFN serum levels in a two-hit model of depression. Behav Brain Res 2019;373:112076. 